\title{
Analisis Kelengkapan Pengisian Data Laporan Operasi di Rumah Sakit Umum Daerah Tidar Kota Magelang Jawa Tengah
}

\author{
Ni Kadek Yulita Sintha Dewi ${ }^{1}$, Sri Setiyarini ${ }^{2}$ \\ Program Studi DIII Rekam Medis Sekolah Vokasi Universitas Gadjah Mada ${ }^{1,2}$ \\ tatayulita58@yahoo.com ${ }^{1}$, sri_setiyarini@ugm.ac.id ${ }^{2}$
}

\begin{abstract}
ABSTRAK
Latar Belakang: Laporan operasi harus segera dibuat setelah pembedahan dan dimasukkan dalam rekam kesehatan. Catatan operasi yang terlalu singkat dapat mengakibatkan ketidakjelasan urutan prosedur dan hal tersebut dapat menimbulkan permasalahan serius terutama bila sampai di pengadilan. Berdasarkan pengamatan saat studi pendahuluan bulan Maret 2016 di Rumah Sakit Umum Daerah Tidar Kota Magelang, peneliti menemukan masih banyak terdapat pengisian laporan operasi yang belum lengkap.

Tujuan: Mengetahui persentase kelengkapan dan ketidaklengkapan pengisian data laporan operasi di Rumah Sakit Umum Daerah Tidar Kota Magelang.

Metode Penelitian: Jenis penelitian yang dilakukan dalam penelitian ini adalah penelitian deskriptif dengan pendekatan kuantitatif. Rancangan Penelitian yang digunakan dalam penelitian ini adalah deskriptif prospektif melalui deskriptif observasional.

Hasil: Hasil penelitian yang berjudul analisis kelengkapan pengisian data laporan operasi di Rumah Sakit Umum Daeran Tidar Kota Magelang adalah kelengkapan pengisian data laporan operasi mencapai $70,08 \%$, ketidaklengkapan mencapai $2,75 \%$ dan ketidakterisian mencapai $27,17 \%$. Analisis kuantitatif ke 4 komponen utama yaitu kelengkapan identifikasi $74,67 \%$, autentikasi $90 \%$, pengisian laporan penting $70,46 \%$ dan pendokumentasian yang baik $57 \%$. Dari hasil tersebut untuk hasil paling tinggi dan rendah pada komponen identifikasi jenis kelamin $96 \%$ dan no register $11 \%$, komponen autentikasi tanda tangan/nama terang dokter ahli bedah $90 \%$, komponen pengisian laporan penting laporan operasi $100 \%$ dan nama perawat $34 \%$, pendokumentasian yang baik tanggal operasi $96 \%$ dan lama operasi berlangsung $13 \%$.
\end{abstract}

Kata Kunci: Laporan Operasi, Analisis Kelengkapan.

\begin{abstract}
Background: the report of the operation should be made after the surgery and included in the health record. the operating record too short can result in the obscurity of the order procedure and it can cause serious problems especially when arriving at the Court. Based on the observation that has been made by researchers at the time of the preliminary study in March 2016 at Regional public hospital Tidar Magelang city, researchers found many still operating report charging that there isn't yet completed.

Objective: to know the percentage of completeness and incompleteness data reportoperations at Regional public hospital Tidar Magelang.

Method: the type of research conducted in this research is descriptive through descriptive observational.

Results: results of the study entitled analysis of completeness of data reporting operation in a public hospital Tidar Magelang city Daeran is the completeness of data reporting the operation reached $70,08 \%$, incompleteness reach $2.75 \%$ and reached ketidakterisian $27,17 \%$. Quantitative analysis to the 4 main components namely the completeness of the identification and authentication $74,67 \%$, 90\%, critical report charging $70.46 \%$ and $57 \%$ of good documentation. Of those results to the results of themosthigh and low on the identification of the gender component is $96 \%$ and 11\%,register no components of the authentication signature/name of the light surgeons $90 \%$, an important report charging components operating reports $100 \%$ and $34 \%$ of nurse name, good documentation of the date of operation $96 \%$ and long operation lasted $13 \%$.
\end{abstract}

Keyword: Operating Report, Analysis Of Completeness. 


\section{PENDAHULUAN}

Dalam melengkapi dan membuat rekam medis perlu adanya tenaga kesehatan yang berwenang untuk mengisi secara lengkap data rekam medis. UU Republik Indonesia no. 29 tahun 2004 pasal 46 tenaga kesehatan yaitu tenaga yang bertanggung jawab dalam mengisi rekam medis adalah dokter atau dokter gigi dan rekam medis harus segera dilengkapi setelah pasien selesai menerima pelayanan kesehatan. Setiap catatan rekam medis harus dibubuhi nama, waktu, dan tanda tangan petugas yang memberikan pelayanan atau tindakan.

Laporan operasi harus segera dibuat setelah pembedahan dan dimasukkan dalam rekam kesehatan. Bila terjadi penundaan dalam pembuatannya maka informasi tentang pembedahan harus dimasukkan dalam catatan perkembangan, perlu diperhatikan catatan operasi yang terlalu singkat dapat mengakibatkan ketidakjelasan urutan prosedur dan hal tersebut dapat menimbulkan permasalahan serius terutama bila sampai di pengadilan (Hatta, 2010).

Setiap pasien yang mendapatkan tindakan operasi hasil tindakan bedahnya harus segera diisi di lembar laporan operasi. Laporan operasi diisi dengan lengkap dan ditanda tangani oleh dokter yang melakukan operasi. Dokter tidak melengkapi laporan operasi karena dokter terlalu sibuk dan banyak hal lain yang mempengaruhi misalnya dokter terburu-buru sehingga tidak sempat mengisi lengkap laporan operasi. Petugas rekam medis khususnya bagian assembling harus memeriksa kembali kelengkapan laporan operasi, yang harus diperiksa adalah Nama pasien, Alamat, No telepon, Umur, Ruangan/kelas, Nama ahli bedah, Nama asisten, Nama ahli anastesi, Jenis anastesi, Diagnosa pre- operasi, Diagnosa post-operasi, Tindakan operasi, Klasifikasi, Jaringan yang di insisi, Jenis operasi, Tanggal operasi, Jam operasi dimulai, Jam operasi selesai, Laporan operasi, dan Tanda tangan dokter ahli bedah. Kelengkapan laporan operasi juga untuk mengukur mutu pelayanan yang diberikan rumah sakit, mengukur mutu rekam medis, dan untuk pendokumentasian yang baik (Huffman,1994).
Berdasarkan pengamatan yang telah dilakukan oleh peneliti pada saat studi pendahuluan bulan Maret 2016 di Rumah Sakit Umum Daerah Tidar Kota Magelang, peneliti mengambil sampel 20 berkas rekam medis yang ada tindakan operasi, peneliti menemukan masih banyak terdapat pengisian laporan operasi yang belum lengkap seperti nomor register, nama ahli bedah, nama asisten bedah, nama perawat, jenis anestesi, macam pembedahan, jaringan yang dieksisi, dikirim untuk pemeriksaan PA, jam operasi dimulai, jam operasi selesai, lama operasi berlangsung dan keterangan keadaan pasien keluar. Bahkan ada beberapa lembar laporan operasi yang tidak berisi identitas sosial pasien dan nomor rekam medis yang semestinya itu adalah hal penting yang perlu diisi dan diperhatikan. Berdasarkan wawancara kepada petugas rekam medis salah satu faktor yang mempengaruhi adalah Dokter dan perawat terlalu sibuk dan terburu-buru dalam melaksanakan tugasnya. Permasalahan ini yang membuat peneliti tertarik untuk menganalisis kelengkapan pengisian data laporan operasi dan mengetahui persentase pengisian data laporan operasi di Rumah Sakit Umum Tidar Kota Magelang, sehingga jika banyak ditemukan ketidakkelengkapan pengisian data laporan operasi sangat penting diisi dengan lengkap agar tidak menimbulkan masalah kedepannya. Kelengkapan pengisian data laporan operasi dapat juga digunakan untuk mengukur mutu rekam medis dan mutu pelayanan yang diberikan rumah sakit.

Penelitian ini bertujuan untuk mengetahui persentase kelengkapan dan ketidaklengkapan pengisian data laporan operasi di Rumah Sakit Umum Daerah Tidar Kota Magelang.

\section{KAJIAN PUSTAKA \\ Analisis Kuantitatif}

Untuk melakukan analisis kuantitatif dapat menggunankan empat komponen utama pada analisis yaitu sebagai berikut; identitas pasien pada setiap lembar rekam medis, autentikasi dokter pada setiap tempat yang ditentukan, pengisian laporan yang penting pada berkas rekam medis dan pendokumentaisan yang baik. 


\section{Laporan operasi}

Menurut Huffman (1994), Laporan operasi merupakan prosedur pembedahan terhadap pasien, isinya merupakan informasi mengenai diagnose pre dan pasca operasi, deskripsi tentang prosedur pembedahan, Diagnosa pre-operasi harus tercatat di catatan medis sebelum pembedahan.

\section{METODE PENELITIAN}

Jenis penelitian yang dilakukan dalam penelitian ini adalah penelitian deskriptif dengan pendekatan kuantitatif. Rancangan Penelitian yang digunakan dalam penelitian ini adalah deskriptif prospektif melalui deskriptif observasional (Sugiyono, 2014).

\section{HASIL DAN PEMBAHASAN Hasil}

Hasil penelitian yang berjudul analisis kelengkapan pengisian data laporan operasi di Rumah Sakit Umum Daerah Tidar Kota Magelang adalah kelengkapan pengisian data laporan operasi mencapai 70,08\%, ketidaklengkapan mencapai 2,75\% dan ketidakterisian mencapai 27,17\%. Analisis kuantitatif ke 4 komponen utama yaitu kelengkapan identifikasi 74,67\%, autentikasi $90 \%$, pengisian laporan penting $70,46 \%$ dan pendokumentasian yang baik 57\%. Dari hasil tersebut untuk hasil paling tinggi dan rendah pada komponen identifikasi jenis kelamin $96 \%$ dan no register $11 \%$, komponen autentikasi tanda tangan/nama terang dokter ahli bedah $90 \%$, komponen pengisian laporan penting laporan operasi $100 \%$ dan nama perawat $34 \%$, pendokumentasian yang baik tanggal operasi $96 \%$ dan lama operasi berlangsung $13 \%$. Berikut grafik 4 komponen utama analisis:

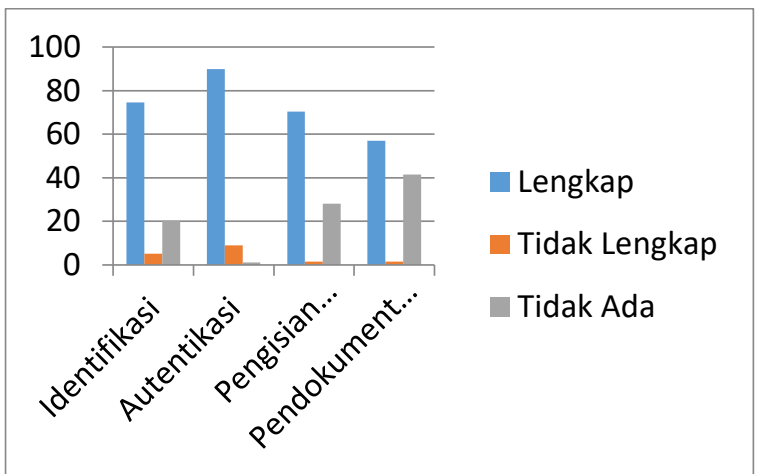

Gambar 1. Komponen Utama Analisis

\section{Pembahasan}

Analisis untuk mengetahui kelengkapan pengisian pada item-item berkas rekam medis dilakukan melalui analisis kuantitatif berkas rekam medis. Untuk melakukan analisis kuantitatif menggunakan 4 komponen utama yaitu identifikasi, autentikasi, pengisian laporan penting dan pendokumentasian yang baik. Kelengkapan komponen utama pada analisis kuantitatif pengisian data laporan operasi identifikasi $74,67 \%$, autentikasi $90 \%$, pengisian laporan penting $70,46 \%$ dan pendokumentasian yang baik $57 \%$.

Dari hasil analisis kuantitatif 4 komponen utama untuk pengisian data laporan operasi di Rumah Sakit Tidar Kota Magelang diketahui hasil paling tinggi dan rendah pada komponen identifikasi jenis kelamin $96 \%$ dan no register $11 \%$, komponen autentikasi tanda tangan/nama terang dokter ahli bedah 90\%, komponen pengisian laporan penting laporan operasi $100 \%$ dan nama perawat $34 \%$, pendokumentasian yang baik tanggal operasi $96 \%$ dan lama operasi berlangsung $13 \%$.

\section{KESIMPULAN \& SARAN \\ Kesimpulan}

Pengisian data laporan operasi di Rumah Sakit Umum Daeran Tidar Kota Magelang kelengkapan mencapai 70,08\%, ketidaklengkapan mencapai $2,75 \%$ dan ketidakterisian mencapai 27,17\%.

Analisis kuantitatif ke 4 komponen utama yaitu kelengkapan identifikasi $74,67 \%$, autentikasi $90 \%$, pengisian laporan penting 70,46\% dan pendokumentasian yang baik $57 \%$. Dari hasil tersebut untuk hasil paling tinggi dan rendah pada komponen identifikasi jenis kelamin $96 \%$ dan no register $11 \%$, komponen autentikasi tanda tangan/nama terang dokter ahli bedah $90 \%$, komponen pengisian laporan penting laporan operasi $100 \%$ dan nama perawat $34 \%$, pendokumentasian yang baik tanggal operasi $96 \%$ dan lama operasi berlangsung $13 \%$.

\section{Saran}

1. Sebaiknya rumah sakit membuat Standar Operasional Prosedur terkait pengisian data laporan operasi agar 
tercapainya kelengkapan dan keseragaman dalam pengisiannya.

2. Diperlukan penelitiaan lebih lanjut untuk mengetahui faktor penyebab ketidaklengkapan pengisian data laporan operasi tersebut.

3. Perlu adanya sosialisasi kepada dokter, perawat dan petugas rekam medis dalam pengisian data laporan operasi

4. untuk mencapai kelengkapan dan keseragaman dalam pengisiannya.

\section{DAFTAR PUSTAKA}

Hatta, G. R. (2011). Pedoman Manajemen Informasi Kesehatan di Sarana Pelayanan Kesehatan. Jakarta: Universitas Indonesia Press.

Huffman, E. K. (1994). Health Information Management. Illinois: Phsycians' Record Company.

Kepmenkes RI nomor 129/Menkes/SK/II/2008 tentang Standar Pelayanan Minimal Rumah Sakit. WWw.depkes.go.id. Diakses tanggal 29 Mei 2016.

Sugiyono. (2014). Metode Penelitian Kuantitatif, Kualitatif dan R\&D. Bandung: Alfabeta

Undang-undang RI Nomor 29. (2004). Praktik Kedokteran. [Diakses 31 Oktober 2015] 